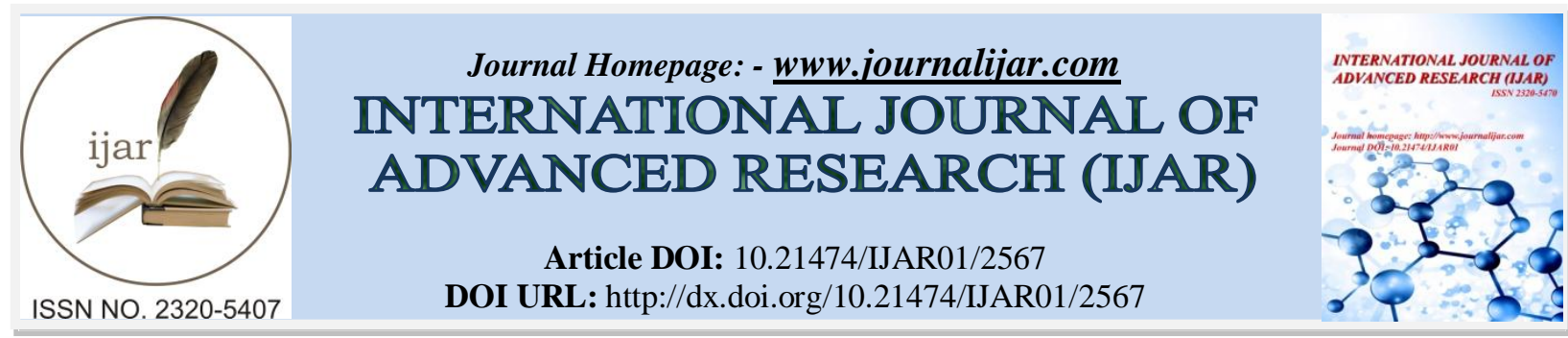

\title{
RESEARCH ARTICLE \\ LUMBOSACRAL BONE DENSITOMETRY IN CHILDREN WITH \\ B-THLASSEMIA MAJOR.
}

\author{
Qasim M H Almosawi ${ }^{1}$, Raid M R umran ${ }^{2}$, Alaa Jumaah Nasrawi ${ }^{3}$, Jasim Mohammed Hashim ${ }^{4}$ and Aymen \\ A. Al-bakaa 5 . \\ 1. M,B,Ch,B.,CABP,MSc., Department of Pediatrics, College of Medicine, University of Kufa, AlZahraa teaching \\ hospital, Najaf, Iraq. \\ 2. Ass.Professor of pediatrics Department of Pediatrics, College of Medicine, University of Kufa, AlZahraa \\ teaching hospital, Najaf, Iraq . \\ 3. Professor of pediatrics Department of Pediatrics, College of Medicine, University of Kufa, AlZahraa teaching \\ hospital, Najaf, Iraq. \\ 4. Ass. Professor of pediatrics FICMS,CABP.
}

\section{Manuscript Info}

(...........................

Manuscript History

Received: 27 October 2016

Final Accepted: 25 November 2016

Published: December 2016

Key words:-

Regular assessment of BMD, to detect any skeletal changes before development of osteoporosis and thus overcoming pathological fractures.

\section{Abstract}

Background: Skeletal changes and bone complications in patients with beta thalassemia major are common and risky. We aim in this study to early detection of low bone density in children with thalassemia major thus overcome any asymptomatic skeletal changes and pathological fractures.

The methods: this study is a cross sectional conducted in the center of hereditary blood disorders in alzahra teaching hospital for the period between $1^{\text {st }}$ of October 2011 to end of November 2012. Fifty, randomly selected (selecting one patients every five of them) beta thalassemia major patients from a total of ( 685 patients) registered in the centre were evaluated for bone marrow densitometry ( BMD). Patients were classified according to their ages in 3 main groups, group A ( $2-5 \mathrm{yr})$, group B ( $6-10 \mathrm{yr})$ and group $C(11-15$ yr $)$. Dual energy $x$-ray absorptiometry

( DEXA) was performed in lumbar regions of those patients . The Zscores were measured from bone density values according to age and gender. The $\mathrm{Z}$ score less than -2.5 was taken as cut off value for osteoporosis, and between -1 and -2.5 as osteopenia. Biochemical and hormonal parameters were recorded and analyzed .

Results: The patient age mean was ( $15 \pm 5.5$ years ) and BMD mean of spine was $(-2.6500+/-0.9)$. Mean $\mathrm{Hb}$. Was $(9.01 \mathrm{~g} / \mathrm{dl})$. All groups of patients with high serum Ferritin level, and (10\%) with hypocalcemia , $(26 \%)$ had hypophosphatemia , (38\%) with high alkaline phosphates enzyme level. BMD was low in all patients of groups C ( $100 \%),(77.78 \%)$ of group B and $(52.63 \%)$ of group A $(p=0.048)$, there is a significant relation between high levels of serum ferritin and BMD ( $p=0.0046)$ While there is no significant relation between S.Ca, S.Ph., S.ALP level and BMD .

Conclusion: present study show that patient of beta thalassemia major may show evidence of low BMD even in younger age group, and 
those with no clear clinical presentation of bone disease.

Copy Right, IJAR, 2016,. All rights reserved.

\section{Introduction:-}

Thalassemias are genetic disorders in globin chain production. Thalassemia syndromes are the most common genetic disorder on world-wide bases which is inhereted as an autosomal recessive bases ${ }^{[1]}$

Thalassemia syndromes either include defect in production of alpha $\alpha$ globin chain where $\alpha$ thalassemia are usually caused deletion of one or more globin gene or the defect is in the $\beta$ chain production. In $\beta$ thalassemia the condition may also be due to gene deletion but more commonly is the consequence of abnormalities in the reading or processing of DNA. ${ }^{[2]}$

Bone complications the bone pathological changes can be seen only in poorly controlled thalassemic patients because regular blood transfusion and well controlled hemoglobin levels may prevents these bony deformities. These deformities will be apparent after one year inform of trabecular changes and cystic formation in small bone and thickening of the cortex and increase of modularly space of long. Skull x-rays will show the characteristics picture of "hair-on-end" appearances. ${ }^{[3] . ~ T h a l a s s e m i a ~ f a c i e s ~ o c c u r ~ b e c a u s e ~ o f ~ o v e r g r o w t h ~ o f ~ m a x i l l a ~ a n d ~ a b s e n c e ~ o f ~}$ cavitation of nasal sinuses that lead to prominence of upper incisors and separation of orbits ${ }^{[3,4]}$

\section{Osteoporosis Osteopenia Syndrome (OOS):-}

Osteoporosis is a disease of skeletal system that is characterized by low bone density and microarchitectural changes that lead to increase bone fragility and easy fracture . ${ }^{[5]}$ With improvement in life expectancy of thalassemic patient, osteopenia osteoporosis syndrome (OOS) is an important cause of bone pain and factures in those patients. ${ }^{[6]}$

Many researches proves a decreased in bone mass in thalassemic patients ( chatterjee , 2000 ; Morabito , 2004 ; Pignatti , 2006b ; Chan , 2002 ; Voskaridou , 2003 ). ${ }^{[7]}$ The causes of OOS in thalassemia syndromes are multifactorial such as bone marrow expansion as a result of ineffective erythropoiesis , anemia, haemosiderosis, delayed puperty , use of chelating agents, multible endocrinopathies, low level of vitamin D and genetic factors [8]

\section{Diagnosis and investigations:-}

Those patients are commonly presented by pain in the bone and it may be associated with past history of fractures . about $20 \%$ of patient have no clinically apparent sign and symptoms. ${ }^{[9]}$

\section{DEXA scan:-}

It is the best way to assess the bone mineral density (BMD).

Fig.1:- WHO criteria for diagnosis of OOS. ${ }^{[10]}$

\section{Osteoporosis}

BMD > 2.5 SD below the young normal mean ( $\mathrm{T}$-score ) or standard deviation in relation to patient's age ( Z-score ) .

Osteopenia

BMD > 1.5 - 2.5 SD below the young normal mean ( $\mathrm{T}-$ score ) .

\section{Biochemical:-}

All patients should be assessed in the following biochemical study: $25(\mathrm{OH})$ vitamin D3, paraathyroidhormones, calcium, phosphate, liver function tests, ( alkaline phosphatase, ALT , billirubin , albumin ), FSH , LH , testosterone and estradiol assays

\section{Radiology:-}

Antero-posterior and lateral X-ray of the spine to exclude fractures. 


\section{MRI:-}

Magnetic resonance imagaing (MRI) of the spine should be done to assess the extramedullary erythropoiesis , and also to check for other bone deformities.

\section{Evaluation of iron load and chelating agent:- Management ${ }^{[9]}$}

The goal of managements is to increase BMD score and decrease the risk of fracture.

\section{Therapeutic options:-}

A lot of treatment modality are present for treating thalassemic patent with osteopenia-osteoporosis .The choice of treatment was determined by the patient age, the thalassemia type such as frequency of blood transfusion , severity of sign and symptom, previous fractures, treatment taken, other of risk factors of nephrocalcinosis and associated hypogonadism, hyperparathyroidism. ${ }^{[9]}$

Fig.2:- Therapeutic options for OOS. ${ }^{[10]}$

Diet and excersice .

Vit.D and calcium supplementation .

Sex hormones replacements in HRT.

Anti-resorption agents -Bisphosphonate .

Combination therapy - Bisphosphonate + HRT.

\section{Monitoring of treatment:-}

The management should be followed by biochemical parameters and DEXA scan should be done to the spine and neck of femoral to calculate the T-scores. An increase of $1-2 \%$ each year is suggested in the neck of femur. After 3 years of pamidronate, usually the BMD effect remain the same. Also long -time treatment for more than 5 years is not recommended as it may cause osteosclerosis.

Management of hypogonadism must be monitored from assessment of serum sex steroid levels. Vitamin D therapy may carry the risk of nephrocalcinosis and bisphpsphonate so it should be given with caution. Thalassemic patients who is on thyroxine and steroid treatment should be monitored because excess replacement can augment osteoporosis . ${ }^{[40]}$

Bone densitometry is used to prove osteoporosis and to determine the risk of future fracture. It measures the bone density the hip, vertebra, forearm, and femur.

Bone densitometry may be conducted by using x-rays, dual-energy x-ray absorptiometry (DEXA or DXA) or by quantitative CT scanning using special software. Ordinary $\mathrm{X}$-rays may show weak bones. However, at the time where bone weakness is clear on x-rays, the treatment is to late be successful. Bone densitometry testing can detect reduced bone density at earlier grade so the treatment may be helpful. ${ }^{[11]}$

First, BMD result is compared with the BMD results from a young healthy (25-35 years old) of similar gender and race. The standard deviation (SD) is the difference between BMD and that of the young healthy adults. This result is called T-score. When the T-scores positive it is mean that the bone is healthy and strong; when the T-scores is negative it is mean that the bone is weak.

The WHO define the osteoporosis according to the following figure ${ }^{[12]}$ : 


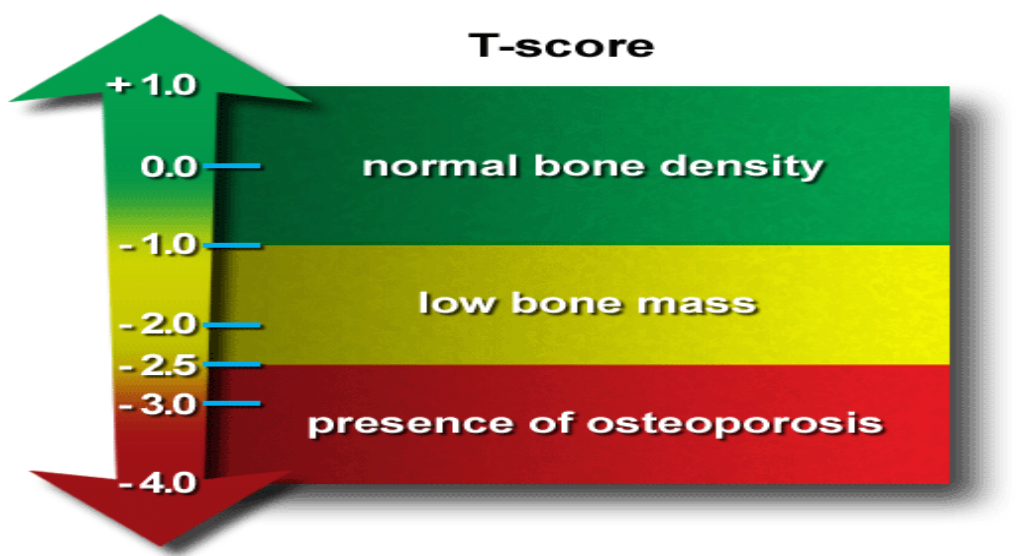

$>$ A T-score within $1 \mathrm{SD}(+1$ or -1$)$ of the young adult mean indicates normal bone density.

$>$ A T-score of 1 to $2.5 \mathrm{SD}$ below the young adult mean (-1 to - 2.5 SD) indicates low bone mass.

$>$ A T-score of $\geq 2.5 \mathrm{SD}$ below the young adult mean $(>-2.5 \mathrm{SD})$ indicates the presence of osteoporosis.

The Methods:-

A total number of fifty (50) beta thalassemia major, regularly transfused patients at Al-zahraa' teaching hospital in thalassemia centre containing ( 685 registered patients ) were randomly selected from visitors of that centre selecting one patients every five of them in a cross sectional study from $1^{\text {st }}$. of October 2011 to $30^{\text {th }}$ of November 2012 . With ages between ( $2-15$ ) years age.Permission had been taken from patients for legal and ethical purposes . Bone mineral densit ( BMD) of lumbar region ( L2 - L 4) using deual X-ray absorbiometry scan (DEXA scan ), ( Dexxuim3 osteosys) was done by a radiologist at Al-Sader teaching hospital / Alnajaf city .Patient sent in a regular schedule, as two patients / week separately in a total period of ( 12 months ). Results collected and interpretated depending on WHO diagnosis criteria of BMD when T-score $<(-2.5)$ considered as osteoporosis and between ( -1 to -2.5 ) as osteopenia. Blood collected, analyzed for : S.Ca., S.Ph., S.ALP, PTH , S.ferritin for each patient. Data interpretated using SPSS version 18 .Results considered stastically significant with $(p$ value $<0.05)$.

\section{The Results:-}

Fifty ( 50 ) patients, $37(74 \%$ ) were males and 13 ( $26 \%$ ) were females, age ranged( 2 years - 15 years), patients divided into mainly 3 age groups as shown in (fig. :4).
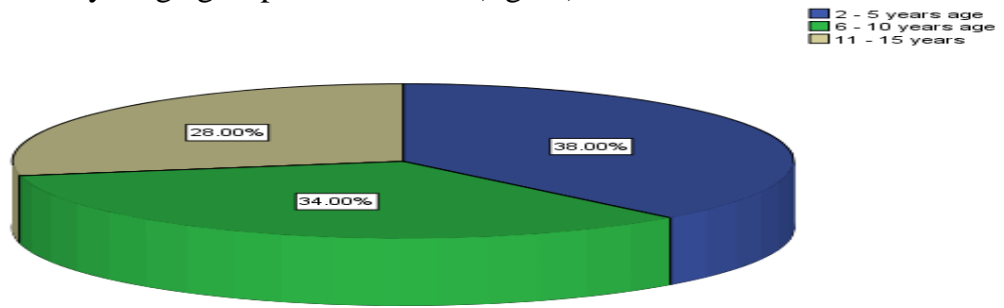

Fig 4:- Age distribution of patients included in the study.

Table . 1:- Mean , SD and percentages of patients with abnormal DEXA scan

\begin{tabular}{|c|c|c|c|c|c|}
\hline \multicolumn{2}{|c|}{ NO. } & Mean & SD & $\begin{array}{c}\text { Osteopenia } \\
n=6\end{array}$ & $\begin{array}{c}\text { Osteoporosis } \\
n=31\end{array}$ \\
\hline Z-score & 50 & -2.6500 & 8.23407 & $12 \%$ & $62 \%$ \\
\hline T-score & 50 & -3.9596 & 6.46615 & $12 \%$ & $62 \%$ \\
\hline
\end{tabular}

Table 2:- Mean , SD , and ranges of all parameters studied.

\begin{tabular}{|l|l|l|l|}
\hline \multicolumn{1}{|c|}{ Parameters } & Reference ranges & \multicolumn{1}{c|}{ Mean } & Std. Deviation \\
\hline PTH level (pg./ml.) & $9-65$ & 33.6200 & 19.11820 \\
\hline Serum Ferritin (ng/mL) & $30-300$ & 3767.1000 & 4488.68780 \\
\hline $\begin{array}{l}\text { Serum calcium } \\
(\mathrm{mg} . / \mathrm{dl})\end{array}$ & $8-11$ & 8.6800 & 1.19915 \\
\hline
\end{tabular}




\begin{tabular}{|l|l|l|l|}
\hline $\begin{array}{l}\text { Serum phosphorus } \\
(\mathrm{mg} . / \mathrm{dl} .)\end{array}$ & $3-4.5$ & 3.7300 & 1.03238 \\
\hline Serum ALP (U./ml.) & $60-120$ & 407.3000 & 158.73637 \\
\hline
\end{tabular}

Table 3:- the relation of patient age with DEXA .

\begin{tabular}{|l|l|l|l|}
\hline Age $($ years $)$ & Normal DEXA scan & Abnormal DEXAscan & $p$ value \\
\hline $2-5(n=19)$ & $9(47.36 \%)$ & $10(52.6 \%)$ & 0.048 \\
\hline $6-10(\mathrm{n}=18)$ & $4(22.22 \%)$ & $14(77.7 \%)$ & 0.045 \\
\hline $11-15(\mathrm{n}=13)$ & $0(0 \%)$ & $14(100 \%)$ & \\
\hline
\end{tabular}

Hemoglobin level for all patients was above ( $8 \mathrm{mg} . / \mathrm{dl}$.) ( mean $=9.0187$ ), related to readings of DEXA scan for normal and abnormal readings, there was no significant difference between two groups $(\mathrm{p}$ value $=0.4)$. ; s.ca , s.ph. and s.ALP show no significant effect of them on DEXA scan readings in their normal or abnormal values . Parathyroid hormone levels ranges ( $60.4+/-19.9$ to 61.3+/-30.2 ) in normal and abnormal DEXA readings respectively also show no significance. All 50 patients in all groups showed high levels of their s.ferritin $($ mean $=$ 3767.1000 ) with significant changes in DEXA readings (Z-score > -2.5 or more ) with those of elevated s.ferritin (>1000 ng./ml.)

Table.4:- Biochemical parameters and their relations with DEXA scan .

\begin{tabular}{|l|l|l|l|l|}
\hline Parameter & Mean & Normal DEXA & Abnormal DEXA & P value \\
\hline Hb. level & 9.0187 & $8.2+/-0.9$ & $8+/-1.1$ & 0.4 \\
\hline S.calcium & $8-11 \mathrm{mg} . / \mathrm{dl}$ & $8+/-0.9$ & $8.8+/-1.2$ & 0.644 \\
\hline S.phosphorus & $3-4.5 \mathrm{mg} . / \mathrm{dl}$. & $.5 .7+/-0.97$ & $5.31+/-1.25$ & 0.887 \\
\hline S.AlP & $60-120 \mathrm{U} . / \mathrm{ml}$. & $307.7+/ 44.4$ & $344.5+/ 1.33$ & 0.229 \\
\hline PTH & $9-65 \mathrm{pg} . / \mathrm{ml}$. & $60.4+/-19.9$ & $61.3+/-30.2$ & 0.892 \\
\hline S.ferritin & $30-300 \mathrm{ng} / \mathrm{mL}$ & $-2.2+/-0.33$ & $-6.6+/-2.3$ & 0.00466 \\
\hline
\end{tabular}

\section{Discussion:-}

The incidence of osteoporosis in thalassemic patients have an average of $90 \%$ (range 52-96\%) ${ }^{[13]}$, and the fractures incidence was $70 \%{ }^{[14]}$.

The pathogenesis of osteoporosis could be a consequence of anemia on bone metabolism, or secondary to hemosiderosis of various endocrine glands, hepatic dysfunction, chronic illness and chelation therapy. ${ }^{[15]}$

Karimi et al. ${ }^{[16]}$, studied BMD by DEXA in Iranian patients with beta thalassemia major and intermediate and found significant correlation between low bone mass and low $\mathrm{Hb}$ level.In current study, Hb.level show no any significant effect on BMD in all age groups included $(p=0.4)$ that may be explained by including those patients with controlled Hb.level that were 9g./dl. and above .

Studies by Benigno et al. ${ }^{[17]}$, showed relationship between BMD Z- scores and chronological age but without significance. In currnt study, there was a statistical significance $(\mathrm{p}=0.048)$ between chronological age and BMD scores explained by that increasing in age making patient more susceptible to skeletal changes such as widening in trabecular bone and so decrease in BMD (table :3).

As all our patients had serum ferritin levels above $1500 \mathrm{ng} / \mathrm{ml}$, it is possible to hypothesize negative effect of iron overload on degree of bone mineralization, so there was statistical significance between level of serum ferritin in high levels and BMD in an inverse way. ${ }^{[18]}$ No available studies present relating high serum ferritin and low BMD.

We noted a high incidence of hyperphosphatemia both in patient and control with abnormal DEXA and there was no statistical significance between phosphorus levels and $\mathrm{Z}$ scores $(p=0.887)$.

The present study (38\%) had hyperparathyroidism which could be explained probably by low vitaminD levels that show no significane effect on BMD $(p=0.892)$. 


\section{Conclusions:-}

The presence of low BMD in patients with beta thalassemia major inspite of absence of clinical symptoms related such as bone pain. so they should receive correct and early detection and management to prevent excessive bone expansion and thus decrease in BMD

\section{Recommendations:-}

Children with beta thalassemia major should have their annular DEXA scan as part of regular follow up of BMD , to detect any skeletal changes and so earlier and prompt managmet before development of osteoporosis overcoming pathological fractures .

\section{References:-}

1. Edwar J.Hemoglobin variant Associated with Hemolytic Anemia , Altered Oxygen Affinity, And methmoglobinemias In : Hematology : Basic principles and practice, $3^{\text {rd }}$ ed , Philadelphia, Churchill Living Stone, $2000: 531-532$.

2. Mentzer W. Thalassemia syndrome. In Rudolph's A, Hoffman J, Rudolph's C (eds). Rudolph's Pediatrics $20^{\text {th }}$ ed. Prentice Hall International, INC. United State of America, 1996 : 1209-1210.ss

3. Chan YI ,Li CK, Chu WC . Deferoxamine induced bone dysplasia in tha distal femur and patella of pediatric patients and young adult. AMJ Roentgenol. 2000; $1561-63$

4. Desanctis V, Savarino L, Stea S . microstructural analysis of sever bone lesions in seven thalassemic patients treated with deferoxamine. Calcif tissue Int $2000 ; 40: 796-98$.

5. Vogel M, Anderson LJ, Holden S, Deanfield JE, Pennell DJ , Walker JM. Tissue Doppler echocardiography in patient with thalassemia detect early myocardial dysfunction related to myocardial iron overload. Eur Heart $\mathbf{J}$ 2003; $24: 113-19$.

6. Cazzola M, Borgna-Pignatti C, Locatelli F, Ponchio L, Beguin Y, De Stefano P . A moderate transfusion regimen may reduce iron loading in beta-thalassemia major without producing excessive expansion of erythropoiesis. Transfusion $1997 ; 37: 135$.

7. Karvounis HI, Zaglavara TA, Parharidis GE, Nouskas IG, Hassapopoulou EP, Gemitzis KD , Louridas GE . An angiotensin -converting enzyme inhibitor improves left ventricular systolic and diastolic function in transfusion dependent patients with beta-thalassemia major . Am Heart J 2001; 141: 281.

8. Anand IS , Chandrashekhar Y, Ferrari R, Poole- Wilson PA, Harris PC . Pathogenesis of oedema in chronic sever anemia: study of body water and sodium, renal function, haemodynamic variables, and plasma hormones. Br Heart J $1993 ; 70$ : 357-58.

9. National Osteoporosis Foundation_Bone Mass Measurement". Archived from the original on 2008-03-07. Retrieved 2008-03-20.

10. Borgna-Pignatti C. Thalassemia. A few new tiles in a large mosaic. Haematologica. 2006; 91: 1159-61.

11. Pagana, Kathleen Deska. Mosby's Manual of Diagnostic and Laboratory Tests. St. Louis: Mosby, Inc., 1998.

12. Kroger H, Kotaniemi A, Vainio P, et al. Bone densitometry of the spine and femur in children by dual-energy $\mathrm{x}$ ray absorptiometry. Bone Miner 1992;17:75-85.

13. Jensen CE, Tuck SM, Agnew JE, et al. High prevalence of low bone mass in thalassemia major. $\mathrm{Br} \mathrm{J}$ Hematol. 1998;103(4):911-5.

14. Rund D, Rachmilewitz E. Thalassemia major-older patients, new therapy. Blood Rev. 1995;9:25-32.

15. Voskaridou E, Terpos E. New insights into the pathophysiology and management of osteoporosis in patients with $\beta$-thalassemia. J Hematol. 2004;127(2):127-39.

16. Karimi M, Ghiam AF, Hashemi A, et al. Bone mineral density in beta thalassemia major and intermedia. Indian Pediatr.2007;44:29-32.

17. Benigno V, Bertelloni S, Giampiero I, et al. Effects of thalassemia major on bone mineral density in late adolescence. J Pediatr Endocrinol Metab. 2003;16:337-42.

18. Gratwick, G.M., Bullough, P.G., Bohne, W.H., Markenson, A.L., Peterson, C.M. (1978) Thalassemic osteoarthropathy. Annals of Internal Medicine, 88; 494501. 